\title{
APUNTES METODOLÓGICOS PARA EVALUAR LA EFECTIVIDAD DE UNA LEY*
}

\author{
Rafael CABAlLERO ÁlvareZ**
}

SUMARIO: I. Introducción. II. La ley y sus propósitos. III. Criterios para evaluar una ley. IV. Perspectiva comparada: la experiencia chilena. V. Conclusiones. VI. Bibliografia.

\section{INTRODUCGIÓN}

¿Cuál es la función social de las leyes? ¿Cómo saber si una ley está cumpliendo con los propósitos que le dieron origen? ¿Qué tan eficaz puede ser un instrumento jurídico? ¿Es posible someter a escrutinio una ley? Las respuestas a estas preguntas no son sencillas ni definitivas, pero el planteárselas tendría que ser parte de la técnica legislativa, pues quizá la actividad más importante de los órganos parlamentarios consiste en proponer, discutir, aprobar o modificar leyes, pero ¿con base en qué lo hacen?

Cierto es que los proyectos e iniciativas de ley, así como los proyectos de reforma constitucional, se acompañan invariablemente de una exposición de motivos con amplios argumentos. Sin embargo, es muy probable que en muchos casos tales argumentos no se correspondan con la realidad social, política o económica de un contexto determinado y que ello conduzca a un despropósito de la ley. Por ello, es deseable que existan diagnósticos precisos que justifiquen los ajustes que se hacen a los marcos normativos, lo cual no siempre se cumple, pues en la mayoría de los casos la discusión parlamentaria se da en términos estrictamente políticos, soslayando aspectos técnicos que resultarían contundentes respecto a la pertinencia de una nueva ley o los ajustes de alguna existente. Incluso, la inclusión de

* Artículo recibido el 29 de noviembre de 2017 y aceptado para su publicación el 15 de noviembre de 2018.

** ORCID: 0000-0001-7810-1141. Profesor-investigador en el Centro de Capacitación Judicial Electoral del Tribunal Electoral del Poder Judicial de la Federación. Correo electrónico: rafael.caballero@te.gob.mx.

Boletín Mexicano de Derecho Comparado, nueva serie, año LI, núm. 154, enero-abril de 2019, pp. 411-423. 
información sobre un estado de cosas que se busca cambiar a partir de una modificación a los marcos normativos ayudaría a evitar que la demagogia trace rutas intransitables en los senderos de la ley.

Resulta evidente que la aprobación de una ley no implica una tarea finiquitada, pues siempre estará sujeta a reformas, pero nuevamente: ¿a la luz de qué se realizan esos ajustes?

La intención de este trabajo es reflexionar en torno a cuál es la función práctica que tienen las leyes dentro de una sociedad y sobre cómo calcular en qué medida una ley cumple con un propósito. Para robustecer la discusión, se describe brevemente una experiencia empírica de perspectiva comparada que resulta sumamente interesante e ilustrativa sobre cómo evaluar la efectividad de una ley, en la que, como se verá, se involucra en el proceso a la sociedad civil.

\section{LA LEY Y SUS PROPÓSITOS}

De acuerdo con Guastini, en el lenguaje jurídico, el término "ley" suele utilizarse en dos sentidos diversos y a veces opuestos, uno formal y otro material. El primero se refiere a cualquier acto o documento que, con independencia de su contenido normativo, emana del Poder Legislativo, lo que le permite gozar de un particular régimen jurídico erga omnes; la dimensión material, en cambio, se refiere a cualquier acto o documento que, con independencia del órgano del cual emana, posee normas generales y abstractas (Guastini, 2000: 15 y 16). A partir de este planteamiento, Guastini distingue tres tipos de "leyes":

- Leyes en sentido sólo formal: actos del órgano legislativo desprovistos de contenido normativo, pero dotados, en cambio, de un contenido singular y concreto.

- Leyes en sentido sólo material: actos de órganos no legislativos (en particular, los actos del Ejecutivo) dotados, sin embargo, de contenido normativo.

- Leyes en sentido formal y material a la vez: actos del órgano legislativo provistos de contenido normativo (Guastini, 2000: 15 y 16).

$\mathrm{Al}$ respecto, vale la pena destacar la dimensión material de la ley, que es a final de cuentas donde ésta encuentra su propósito. Ciertamente el

Boletín Mexicano de Derecho Comparado, núm. 154, enero-abril de 2019, pp. 411-423. 
aspecto formal le da mayor consistencia y le concede legitimidad para su aplicación, pero en este caso el elemento material es el que se desea enfatizar. $\mathrm{Al}$ respecto, vale la pena cuestionarse: ¿cuál es el propósito de que exista un sistema normativo?

De acuerdo con Eliseo Muro, las normas jurídicas son pautas que presentan una prescripción de una conducta que se estima obligatoria, por lo que su desacato acarrea una consecuencia jurídica negativa, que es la sanción. Por ello es que el derecho se entiende como "el conjunto de preceptos, reglas o leyes que regulan la actividad humana, ya sea normas impero-atributivas que imponen deberes a ciertos sujetos, conceden facultades, como en el derecho civil, el penal, etcétera" (Muro, 2007: 7). Más adelante, el mismo Muro agrega:

El Estado se adjudicó el monopolio de creación (especialmente a través del Poder Legislativo) y ejecución de las normas jurídicas, para ser fuente de validez formal. Estas normas que emitan los órganos constitucionales deben de ser producto de la reflexión sobre la realidad nacional. Se busca concretizar importantes finalidades, como construir normas e instituciones para encausar la conducta del hombre hacia el desarrollo individual y colectivo, así como estructurar el aparato estatal. En la actualidad no se puede concebir al derecho sin el Estado y viceversa, así, el vocablo "norma" significa escuadra, un instrumento para medir la diferencia de dirección (Muro, 2007: 11 y 12).

De la cita anterior se destacan tres aspectos centrales. En primer lugar, el propósito de un sistema normativo formal y material: regular la convivencia social y organizar el aparato estatal mediante reglas e instituciones. Segundo, la norma como instrumento de dirección, como criterio orientador para concretizar importantes fines. Y tercero, la importancia de que las normas que deriven del ejercicio legislativo sean producto de la reflexión en torno de la realidad nacional.

A la luz de estas premisas adquiere relevancia el hecho de que el legislador aplique ajustes o bien modificaciones más de fondo a una ley en específico, siempre y cuando se acompañen de una reflexión objetiva acerca de la realidad nacional o local, según sea el caso. Ello conduce a la necesidad de avanzar en el perfeccionamiento de la técnica legislativa, a modo de que en ésta se considere cada vez con mayor frecuencia la elaboración de estudios, diagnósticos y consultas que sustenten la creación, 
modificación derogación o abrogación de leyes en prácticamente cualquier materia.

Sólo por poner un ejemplo, piénsese en la materia electoral. Luis Carlos Ugalde y Gustavo Rivera advierten que, aun cuando entre 1986 y $2013,{ }^{1}$ se realizaron siete grandes reformas, muchas de ellas con aportaciones positivas para propiciar mayor equidad, transparencia y legalidad en los procesos electorales, otras tantas han tenido efectos inciertos, justamente debido, en buena parte, a la ausencia de diagnósticos certeros acerca de las fortalezas y debilidades del sistema electoral en su conjunto, así como por la falta de claridad en las metas que se buscaba alcanzar (Ugalde y Rivera, 2014: 11).

Es lógico inferir que los resultados de estudios serios y profesionales ayudarían a contrarrestar esta tendencia advertida por los autores, a fin de orientar el ejercicio legislativo en lo que se refiere a la producción de leyes, aunque muy probablemente, aun cuando así sucediera, la tarea no concluiría en la aprobación y entrada en vigor de éstas. Dado que la ley no es única, acabada ni sempiterna, sino que requiere de ajustes en función de las necesidades que plantee la realidad social o política, la elaboración de diagnósticos tendría que ser un proceso permanente y cíclico, como lo es la propia función legislativa, y en este esfuerzo sería conveniente que se incluyera la revisión de la ley misma, para conocer sus alcances y saber si cumple con los propósitos que se planteó en su origen o con las posteriores modificaciones a que fue sometida.

\section{GRITERIOS PARA EVALUAR UNA LEY}

De acuerdo con el Centro de Estudios Espinosa Yglesias (CEEY), hace alrededor de medio siglo en Europa comenzó a regularse la manera en que se elaboraban las leyes para hacerlas más accesibles y fáciles de comprender; pero en realidad no fue sino hasta los años setenta y principios de los ochenta que comenzaron a introducirse enfoques administrativos para mejorar la calidad sustantiva de la legislación, lo que generó que a partir

1 Habrá que recordar que la más reciente reforma electoral queda fuera del periodo estudiado por los autores, debido a que deriva del decreto de reforma constitucional publicado el 10 de febrero de 2014 en el Diario Oficial de la Federación, que tuvo como resultado la reestructuración de todo el sistema electoral a fin de adoptar un sistema híbrido entre el ámbito federal y el de las entidades federativas.

Esta obra está bajo una Licencia Creative Commons

Atribución-NoComercial-SinDerivar 4.0 Internacional, IIJ-UNAM.

Boletín Mexicano de Derecho Comparado, núm. 154, enero-abril de 2019, pp. 411-423. 
de los noventa comenzara a difundirse extensamente una tendencia por construir marcos conceptuales para aumentar la calidad de la legislación, de tal suerte que en la actualidad, tanto académica como profesionalmente, la calidad de las leyes es una preocupación extendida (CEEY, 2010: 2).

El principal enfoque que se ha adoptado para implementar cierto control sobre la calidad de la legislación es el de la manifestación de impacto regulatorio (Regulatory Impact Assessment, RIA), el cual enfatiza el objetivo de producir legislación efectiva al menor costo social posible. De acuerdo con el mismo CEEY, el RIA fue aplicado, por primera vez, en Estados Unidos en 1974 para calcular el efecto inflacionario de legislación secundaria aparentemente onerosa, por lo que desde 1981 se le considera un requisito para toda regulación social importante (CEEY, 2010: 2).

En 1980, sólo dos países de la Organización para la Cooperación y el Desarrollo Económico (OCDE) aplicaban el enfoque RIA, pero para 1996 ya eran más de la mitad y la tendencia aumentó cuando en 1997 este organismo internacional presentó el Reporte sobre Reforma Regulatoria, en el que recomendaba a los gobiernos "integrar la manifestación de impacto regulatorio en el desarrollo, revisión y reforma de la regulación" (CEEY, 2010: 2).

Los principales criterios planteados por la OCDE para realizar la evaluación de alguna legislación son:

1) Definición correcta del problema. El problema tiene que presentarse en términos precisos, con evidencia adecuada sobre su naturaleza y magnitud, y con una explicación de su origen (en general, los incentivos que enfrentan los actores relevantes).

2) Justificación de la acción estatal. Debe existir evidencia suficiente que sustente la regulación. Las consideraciones básicas son la naturaleza del problema, los costos y beneficios de una instrumentación realista y las alternativas de política pública disponibles (la no acción es la primera de ellas). El análisis detallado de fines y medios son fundamentales para la evaluación retrospectiva.

3) Justificación de la regulación particular. Deben compararse alternativas de acción, tanto regulatorias como no regulatorias (no intervenir, proveer información al público, autorregulación y arreglos basados en incentivos como metas e incentivos financieros o 
comerciales), en las que se tomen en cuenta riesgos, costos, beneficios, efectos distributivos, requisitos administrativos, etcétera.

4) Sustento legal de la regulación. Toda regulación debe respetar el Estado de derecho. Debe enmarcarse apropiadamente en la legislación vigente y los principios generales de certeza, proporcionalidad y equidad. Deben especificarse las partes de la legislación actual que serán modificadas y establecerse adecuadamente la categoría de la nueva disposición.

5) Determinación del ámbito estatal apropiado. Debe justificarse qué nivel de gobierno es responsable de qué tarea en la instrumentación y el monitoreo de la norma. Deben establecerse procedimientos eficaces de coordinación.

6) Comparación de costos y beneficios. Deben calcularse los costos totales esperados y los costos específicos (para ciudadanos, organizaciones, sectores, el aparato del Estado) de cada propuesta regulatoria y las alternativas disponibles. El efecto total debe ser positivo.

7) La distribución de costos en la sociedad debe ser transparente. Hay que establecer explícitamente los cambios en el bienestar relativo de los grupos sociales.

8) Claridad, accesibilidad. La presentación de la norma debe ser tal, que el público interesado pueda consultarla fácilmente y entenderla bien.

9) Consultas. Todos los actores relevantes (privados, públicos, de la sociedad civil organizada) deben tener la oportunidad de opinar sobre la nueva regulación. Las normas deben elaborarse de modo transparente.

10) Explicación de cómo se conseguirá el cumplimiento de las disposiciones. Deben estudiarse los incentivos y el marco institucional de las decisiones de los actores relevantes para asegurar que observen la ley (costos de cumplimiento y de hacer cumplir la ley, trámites). Se presentan parámetros del éxito de la norma (CEEY, 2010: 5-6).

Las premisas planteadas por la OCDE sugieren que la evaluación de la legislación puede realizarse en distintos momentos. En tal sentido, Álvaro Paúl Díaz y Sebastián Soto Velasco, señalan que, de manera general existen dos momentos en los que puede llevarse a cabo la revisión de una ley; el primero, antes de su entrada en vigor, en el cual es posible 
distinguir, a su vez, dos etapas: una antes de que comience el proceso de discusión y análisis, y la segunda como parte ya de este proceso. El segundo momento se produce desde el punto en que el ordenamiento ya ha comenzado a regir, es decir, ex post (Díaz y Soto Velasco, 2009: 586).

En realidad, el momento ex post es el que daría oportunidad propiamente de someter a escrutinio la ley y sus efectos, ya que en el proceso $e x$ ante más bien se estaría hablando de la configuración de ésta. En tal sentido, entre las ventajas que se observan de evaluar una ley ya en vigor se encuentran las siguientes:

- Es posible determinar si la ley fue capaz de cumplir con sus propósitos, lo que tendría un beneficio adicional para los órganos legislativos, en la medida en que podría redituar en el reconocimiento a una adecuada labor legislativa.

- Permite advertir áreas de oportunidad, sentando así las bases para una eventual reforma legislativa.

- Si la legislación padece de efectos colaterales nocivos, será más probable que ellos sean corregidos a través de una modificación legal.

- De la evaluación surgen propuestas de cambio (Díaz y Soto Velasco, 2009: 587).

Adicionalmente, los autores señalan que la evaluación ex post propicia que los parlamentarios no sólo corrijan los errores de leyes aprobadas en el pasado, sino que también tiendan a tener una mirada más de futuro, al recordarles que legislar tiene efectos concretos y medibles. Esto les permitirá adquirir conciencia de que su trabajo puede ser evaluado posteriormente, favoreciendo con ello condiciones que hagan propicia la exigencia de rendición de cuentas o accountability.

Este par de autores identifican varias formas de llevar a cabo una evaluación ex post, las cuales se refieren a lo siguiente:

- Mediante comisiones evaluadoras parlamentarias. Consisten en grupos de legisladores, con cierto nivel de especialización, dedicados específicamente a la evaluación de los resultados de las leyes aprobadas por el mismo Poder Legislativo. El conocimiento legislativo de los integrantes de estas comisiones puede representar una virtud que, sin embargo, podría verse mermada por juicios subjetivos, en función de 
que a final de cuentas son legisladores quienes evalúan la producción parlamentaria.

- A través de una evaluación por parte del servicio destinado a aplicar la ley. Esta opción puede resultar muy efectiva en la medida en que el pulso de la conveniencia y eficacia de la ley lo calcularía la instancia encargada de realizar las acciones reguladas por ésta.

- Por conducto de un servicio público especializado. Esta opción implicaría crear ex profeso un órgano específico del Estado que desarrolle las evaluaciones. ${ }^{2}$

- Mediante una comisión especial dependiente del Parlamento. Las ventajas serían similares a las del servicio público especializado, aunque se sumaría el hecho de mantener una vinculación más estrecha con el Congreso.

- Por parte de un servicio público coordinador de evaluaciones. Este modelo, a diferencia del de servicio público especializado, no implicaría crear una nueva instancia, sino delegar la responsabilidad a una ya existente que funja como coordinadora y que eventualmente pueda apoyarse en contrataciones externas.

- Con el apoyo de una comisión de expertos creada por la ley evaluada. Esta opción consiste en que desde la ley misma se establezca la existencia de una comisión de expertos encargada de evaluar su aplicación, lo que implicaría la creación de órganos ad hoc, que tendrían a su favor un alto nivel de especialización, pero en contra de una naturaleza más bien coyuntural que, por ese carácter perecedero, poco abonaría a la institucionalización de mecanismos de evaluación legislativa.

\section{PERSPECTIVA COMPARADA: LA EXPERIENCIA CHILENA}

Díaz y Soto señalan que la evaluación legislativa ha adquirido una importancia fundamental en la vida normativa de la Unión Europea a

2 En México existe la Comisión Federal de Mejora Regulatoria (Cofemer), que es un órgano administrativo desconcentrado, con autonomía técnica y operativa, sectorizado a la Secretaría de Economía del gobierno federal. Sin embargo, no existe una vinculación directa con el Poder Legislativo, sumado a que su función está más enfocada al marco regulatorio de la actividad económica, por lo que sus aportaciones al proceso de construcción y evaluación de las leyes en general emanadas del Congreso son más bien limitadas.

Esta obra está bajo una Licencia Creative Commons

Atribución-NoComercial-SinDerivar 4.0 Internacional, IIJ-UNAM.

Boletín Mexicano de Derecho Comparado, núm. 154, enero-abril de 2019, pp. 411-423. 
partir de los años noventa, tanto por lo que hace a los estudios ex ante, como a la evaluación ex post. También observan que en Estados Unidos se ha seguido una tendencia similar, que le ha valido al Congreso de aquel país hacerse de una gran capacidad para evaluar leyes, en cuyos procesos tienen participación tanto órganos que dependen del mismo Congreso, como otros de carácter externo, públicos y privados (Díaz y Soto Velasco, 2009: 594). Pero entre estas experiencias internacionales vale la pena destacar un esfuerzo latinoamericano, el desarrollado en Chile ya en pleno siglo XXI.

En diciembre de 2010, la Cámara de Diputados de Chile creó el Departamento de Evaluación de la Ley, con el objetivo de completar el ciclo regulatorio de las normas con estudios que permitan conocer los efectos resultantes de las leyes promulgadas. ${ }^{3}$ En junio de 201 1, la misma Cámara dispuso la creación de un Comité de Diputados para la Evaluación de la Ley, en el cual participa un representante de cada bancada parlamentaria.

Resulta muy importante señalar que la iniciativa chilena contó con el apoyo de la OCDE, instancia que, por conducto de su Comité de Política Regulatoria, aportó su experiencia en el tema y apoyó en la orientación del diseño institucional del Departamento de Evaluación de la Ley, así como acerca de la metodología a utilizar, mediante la realización de seminarios parlamentarios, entre otras estrategias.

Conforme a estos antecedentes, en mayo de 2012, la OCDE publicó el documento intitulado: La evaluación de leyes y regulaciones. El caso de la Cámara de Diputados de Chile, que constituye el primer informe realizado por la División de Política Regulatoria de la Dirección de Gobernanza Pública y Desarrollo Territorial de la OCDE para

ayudar al Poder Legislativo de un país miembro a diseñar un sistema e instituciones que efectúen evaluación de la ley, aprovechando buenas prácticas internacionales. Es, asimismo, una de las primeras iniciativas para apoyar a los órganos legislativos de manera práctica, al revisar la aplicación de la legislación (OECD, 2012: 3).

Este informe concentraba buena parte de la experiencia de la OCDE en análisis comparativos, recapitulando referencias sobre el tema de la evaluación de leyes, particularmente de tipo ex post, en países miembros de

\footnotetext{
3 Según se señala en el sitio electrónico: wrere.evaluaciondelaley.cl.
}

Esta obra está bajo una Licencia Creative Commons Atribución-NoComercial-SinDerivar 4.0 Internacional, IIJ-UNAM. Boletín Mexicano de Derecho Comparado, núm. 154, enero-abril de 2019, pp. 411-423. 
la OCDE. Adicionalmente, se recopilaban ejemplos de buenas prácticas internacionales para un diseño institucional propicio para realizar una efectiva evaluación ex post de la ley, así como de metodologías aplicadas para ello y sobre técnicas utilizadas para incorporar la percepción ciudadana en las metodologías de evaluación.

La experiencia chilena de evaluación de la ley resulta vanguardista y representa un precedente muy significativo en la dinámica parlamentaria de los países de América Latina, pero es aún más reveladora si se considera que en este proceso se buscó involucrar a la ciudadanía. En ese sentido, la metodología adoptada por el Departamento de Evaluación de la Ley otorga particular importancia a la participación tanto de agrupaciones de la sociedad civil relacionadas con la ley que se busca evaluar, como de personas en lo individual. Entre algunas de las bondades que derivan de la participación ciudadana en este proceso se destacan las siguientes:

- Los ciudadanos pueden contribuir a visualizar efectos secundarios inesperados y/o no deseados de las leyes;

- Su participación promueve la transparencia y la rendición de cuentas en el proceso legislativo;

- Su incorporación previene la influencia desmedida de intereses particulares por sobre el interés público en la toma de decisiones.

Este involucramiento ciudadano se materializa mediante la organización de foros ciudadanos, que se definen como espacios de encuentro e intercambio, los cuales bien pueden ser de tipo virtual o presencial, en los que los ciudadanos y las organizaciones sociales tienen la oportunidad de expresar sus opiniones, compartir información y formular sugerencias o propuestas relacionadas con la ley que se desee someter a evaluación. ${ }^{4}$

\footnotetext{
4 En México, en muchas ocasiones en el contexto de discusión de una ley de particular relevancia es común que el Poder Legislativo convoque a foros públicos a distintos sectores de la sociedad, como ha sucedido con leyes en materia electoral, de derechos humanos, de reforma energética, etcétera. Sin embargo, no en todos los casos es posible advertir qué tanto las discusiones y conclusiones generadas en estos espacios se erigen como insumos para el diseño de algún marco normativo en concreto. Al menos esa es la percepción que se genera a partir de las minutas, iniciativas y proyectos que dan cuenta del debate parlamentario.
}

Esta obra está bajo una Licencia Creative Commons

Atribución-NoComercial-SinDerivar 4.0 Internacional, IIJ-UNAM.

Boletin Mexicano de Derecho Comparado, núm. 154, enero-abril de 2019, pp. 41 1-423. 
Esta revista forma parte del acervo de la Biblioteca Jurídica Virtual del Instituto de Investigaciones Jurídicas de la UNAM

De manera general se pueden identificar dos fases en el proceso de evaluación de la ley en Chile, a saber:

1) Primera fase. Consiste en realizar una revisión y elaborar un análisis técnico de la ley en cuestión y de sus normas derivadas, o bien con las que guarda relación, con base en la generación de estadísticas y la recolección de opiniones de expertos y organismos implementadores.

2) Segunda fase. Consiste en identificar la percepción ciudadana acerca de la ley evaluada y su aplicación, especialmente de las personas afectadas directamente por ella.

La infraestructura legislativa chilena para la evaluación de leyes ha permitido que hasta el momento se haya podido llevar a cabo la valoración de los siguientes instrumentos normativos:

- Ley núm. 20.422, que establece normas sobre igualdad de oportunidades e inclusión social de personas con discapacidad.

- Ley núm. 20.413, que determina quiénes pueden ser considerados donantes de órganos y la forma en que pueden manifestar su voluntad.

- Ley núm. 18.600, que establece normas sobre personas con discapacidad mental.

- Ley núm. 20.348, que resguarda el derecho a la igualdad en las remuneraciones.

- Ley núm. 20.000, que sanciona el tráfico ilícito de estupefacientes y sustancias.

- Ley núm. 20.599, que regula la instalación de antenas emisoras y transmisoras de servicios de telecomunicaciones.

- Ley núm. 20.066, de violencia Intrafamiliar.

Como se puede apreciar, la de Chile es una experiencia bastante desarrollada acerca de cómo sujetar a evaluación una ley que, sin duda, se podría emular adaptándola a las circunstancias particulares de cada país y perfeccionándola de forma específica. Es innegable que se trata de un referente muy significativo para destacar la necesidad de adoptar paulatinamente modelos de mejora regulatoria y de evaluación de las leyes, en 
aras de imprimir mayores estándares de profesionalización a la función legislativa, involucrar a la ciudadanía en el desempeño y supervisión de esta función y, principalmente, para generar condiciones que permitan a la ley cumplir con algunos de sus objetivos prácticos para preservar el orden social.

\section{Gonclusiones}

Como cierre de esta colaboración, vale la pena insistir en la importancia de adoptar en México mecanismos permanentes de evaluación de las leyes, no sólo para favorecer el acercamiento de la ciudadanía con el Poder Legislativo y ampliar así las condiciones que contribuyan la rendición de cuentas, sino también para asignar a los marcos normativos parámetros de efectividad que sean susceptibles de medición.

En México existe una infraestructura institucional que podría contribuir a ese objetivo, pero es indispensable vincular más directamente la labor de las instancias que la integran con la función legislativa. Ya se mencionó en páginas anteriores a la Cofemer, pero también se podría considerar a otras instituciones públicas que recopilan información temática por sí mismas, como el Instituto Nacional de Estadística y Geografía (INEGI), al Consejo Nacional de Evaluación de la Política de Desarrollo Social (Coneval), el Instituto Nacional para la Evaluación de la Educación (INEE), o bien sumar el apoyo de institutos de investigación de las múltiples universidades y escuelas de educación superior del país.

Vale la pena recordar que incluso al interior de los órganos legislativos se cuenta con áreas de apoyo a la función parlamentaria, por lo menos en el ámbito federal. En el caso de la Cámara de Diputados se cuenta con cinco áreas de investigación, a saber: el Centro de Estudios de las Finanzas Públicas, el Centro de Estudios de Derecho e Investigaciones Parlamentarias, el Centro de Estudios Sociales y de Opinión Pública, el Centro de Estudios para el Adelanto de las Mujeres y la Equidad de Género, y el Centro de Estudios para el Desarrollo Rural Sustentable y la Soberanía Alimentaria. Por otro lado, el Senado de la República cuenta con el Instituto Belisario Domínguez y el Centro de Estudios Internacionales Gilberto Bosques. Sin embargo, no es común que en la exposición de motivos de las iniciativas legislativas se citen estudios e investigaciones realizadas por estas agencias como parte del caudal argumentativo. De hecho, da la

Esta obra está bajo una Licencia Creative Commons

Atribución-NoComercial-SinDerivar 4.0 Internacional, IIJ-UNAM.

Boletín Mexicano de Derecho Comparado, núm. 154, enero-abril de 2019, pp. 411-423. 
Esta revista forma parte del acervo de la Biblioteca Jurídica Virtual del Instituto de Investigaciones Jurídicas de la UNAM

impresión de que el trabajo que desarrollan es completamente desvinculado de la función legislativa, específicamente en lo que respecta a la parte técnica de elaboración de las leyes.

Sin duda, resulta indispensable que se logre articular esfuerzos de manera sistemática y programática entre todas estas instancias para contar con "mejores" leyes desde su génesis y durante su aplicación.

\section{BIBLIOGRAFÍA}

Centro de Estudios Espinosa Yglesias, 2010, "Proyecto de Evaluación de Leyes. Criterios de Evaluación". Disponible en: http://wrwreceey. org. $m x /$ sites/default/files/ceey-proyectodeevaluaciondeleyes.pdf.

DíAZ, Álvaro Paul y Soto VeLASco, Sebastián, 2009, "Legislar con eficiencia: la importancia de evaluar las leyes", Revista Actualidad Furídica (II). Disponible en: http://papers.ssrn.com/sol3/papers.cfm?abstract_ $i d=2168547$.

Guastini, Riccardo, 2000, "Ley", en Carboneld, Miguel y Pedroza, Susana Thalía (eds.), Elementos de técnica legislativa, México, UNAM, Instituto de Investigaciones Jurídicas. Disponible en: http://biblio.juridicas. unam.mx/libros/1/21/tc.pdf.

Muro Ruiz, Eliseo, 2007, Algunos elementos de la técnica legislativa, México, UNAM, Instituto de Investigaciones Jurídicas. Disponible en: http:// biblio.juridicas.unam.mx/libros/libro.htm?l=2149.

OECD, 2012, La evaluación de leyes y regulaciones. El caso de la Cámara de Diputados de Chile, OECD Publishing.

Ugalde Ramírez, Luis Carlos y Rivera Loret de Mola, Gustavo, 2014, Fortalezas y debilidades del sistema electoral mexicano. Perspectiva estatal e internacional, México, TEPJF. 